\title{
Diurnal changes in the delayed fluorescence response of an ambient light-excited green alga
}

\author{
W. ECKERT ${ }^{*,+}$, F. LEUNERT ${ }^{* *}$, Y.Z. YACOBI ${ }^{*}$, J. KÖHLER ${ }^{* *}$, and E. KURZBAUM ${ }^{* * * * * * * *}$ \\ The Yigal Allon Kinneret Limnological Laboratory, Israel Oceanographic and Limnological Research, Haifa, Israel ${ }^{*}$ \\ Department of Ecosystem, Leibniz Institute of Freshwater Ecology and Inland Fisheries (IGB), Berlin, Germany** \\ Shamir Research Institute, University of Haifa, P.O. Box 97, Qatzrin, Israel ${ }^{* * *}$ \\ Department of Geography and Environmental Studies, University of Haifa, Mount Carmel, Haifa 3498838, Israel ${ }^{* * * *}$
}

\begin{abstract}
Delayed fluorescence (DF) is a characteristic feature of light-excited plant cells caused by the back-reaction of electrons through the electron transport chain. Targeting the response of light-adapted green algae to diurnal light changes, the present study presents novel results of DF measurements in the absence of an artificial excitation light source. Based on a linear relationship between the DF counts and light intensities from 0.15 to $0.65 \mathrm{~W} \mathrm{~m}^{-2}$ during daybreak, we estimated an

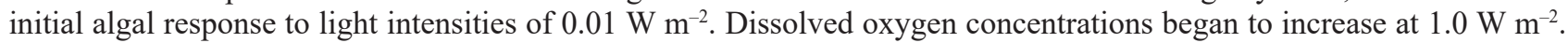
A noon depression similar to that reported for prompt fluorescence occurred above $100 \mathrm{~W} \mathrm{~m}^{-2}$. Our results from multiple day-night cycles emphasize that the DF response is a function of the chlorophyll concentration and of a rapid light adaptation. The DF counts alone cannot provide a reliable unambiguous measure of photosynthetic activity.
\end{abstract}

Additional key words: Chlorella vulgaris; chlorophyll fluorescence; diurnal light cycle; phytoplankton.

\section{Introduction}

Delayed fluorescence (DF) was first described by Strehler and Arnold (1951) as a dark red afterglow from green plants when transferred from light into dark. DF is caused by the backflow of electrons through the electron transport chain (ETC). During this process, the reduced $\mathrm{Q}_{\mathrm{A}}$ delivers an electron to the oxidized reaction center $\left(\mathrm{P} 680^{+}\right)$. An exited $\mathrm{P} 680^{*}$ is formed, that decays to the ground state emitting a fluorescent quantum within the 680-720 nm range (Gerhardt et al. 2005). Compared to prompt fluorescence, probably the most critical feature of the DF is that it originates from electrons, which had previously entered the ETC, and consequently represents solely photosynthetically active chlorophyll (Chl) (Jursinic 1986). During the past 50 years, DF instruments were applied mainly for studying physiological aspects of the reversed electron flow in plant cells (Bertsch 1962, Melcarek and Brown 1977, Avron and Schreiber 1979, Mellvig and Tillberg 1986, Wang et al. 2004, Monti et al. 2005). In addition, there were some phytoplanktonspecific DF applications aimed at the monitoring of photosynthetically active Chl (Krause et al. 1987), algal activity (Yacobi et al. 1998, Kurzbaum et al. 2007), and the density of phytoplankton color classes based on their specific pigmentation (Gerhardt and Bodemer 2000, Istvánovics et al. 2005). DF instruments were successfully tested for their capability to conduct rapid and highly sensitive biotests based on toxicant-induced changes in the DF decay kinetics of green algae and cyanobacteria (Katsumata et al. 2006, Berden-Zrimec et al. 2007, Leunert et al. 2013). A general overview over the various applications of DF can be found in a book chapter by Berden-Zrimec et al. (2010).

Most of the DF-related research has been conducted with custom-made instrumentation that operated according to the same principle as described in the original work (Strehler and Arnold 1951). Dark-adapted plant cells are illuminated by a defined light pulse in an excitation cell followed by photon counting of the signal decay in the dark. The resulting photon counts are a function of the Chl concentration, the intensity of the excitation light, the temperature, the time lag between illumination, and the begin of DF counting and the counting period (Goltsev et al. 2009). Kurzbaum et al. (2007, 2010) used a DFexcitation spectrometer (Gerhardt and Bodemer 1998) to monitor the diurnal DF change in dark-adapted green algae grown under ambient light. They found that during

Received 18 December 2017, accepted 14 June 2018.

${ }^{+}$Corresponding author; e-mail: werner@ocean.org.il

Abbreviations: Chl - chlorophyll; DF - delayed fluorescence; DFI - delayed fluorescence integral; ETC - electron transport chain; $\mathrm{n}$-DFI - normalized delayed fluorescence integral; $\mathrm{PP}$ - primary production.

Acknowledgements: The present study was supported research grant \#: WT 1003/2264 from the German Federal Ministry of Education and Research (BMBF) and Israel Ministry of Science and Technology (MOST). 
daytime the DF counts responded to the ambient light intensity regardless of the preceding dark adaptation. This observation led to our hypothesis that the DF of lightadapted phytoplankton cells excited directly by ambient light could provide useful information about real time phytoplankton activity. Given the dynamic light supply of suspended algae, such a method could provide more realistic information on photosynthetic activity within natural light gradients, such as night-morning transition or attenuation with depth. The present study was aimed at the changes in the DF counts of light-adapted algae exposed to naturally occurring changes in light intensities.

\section{Materials and methods}

Central item of our experimental setup (Fig. 1) was a custom-made DF instrument provided by V. Gerhardt, University of Regensburg, Germany, and similar to the one used by Gerhardt et al. (1981). For our purpose of measuring the DF of ambient light-excited algae without preceding dark adaptation, we had to modify the software of the instrument in a way that allowed for pumping of an algal suspension from an outdoor bioreactor directly into the dark emission cell. Photon counting began with a pump stop. The emitted photons were counted for $60 \mathrm{~s}$ and the sum stored in form of the DF integral (DFI) followed by the determination of the dark rate (background counts after decay) after another $30 \mathrm{~s}$. The instrument was set to automatically subsample the algal suspension in fiveminute intervals throughout the incubation experiment that lasted three to four day-night cycles.

Prior to our experiments, we inoculated a 3-L outdoor bioreactor containing SCM-mineral medium (Moss 1972) with a monoalgal culture of Chlorella vulgaris spec., isolated from the Danube by the late U. Bodemer. The algal suspension was circulated continuously by an aquarium pump and the temperature was maintained between 20 $25^{\circ} \mathrm{C}$ by a temperature controller. For a period of several days, we allowed the algae to adapt to the ambient light conditions until $\mathrm{Chl}$ concentrations reached about $500 \mu \mathrm{g}$ $\mathrm{L}^{-1}$. At the beginning of each experiment, we diluted the culture 1:300 with fresh medium. During the incubation, we followed the Chl $a$ concentration via DF measurements at night by illuminating the dark-adapted cells through the transparent tubing on their way to the counting cell withactinic light, triggered by a timer. The calibration factor for converting the DFI into Chl units was determined prior to the experiment by measuring the DFI in a dilution series of dark-adapted subsamples from an exponentially growing Chlorella culture. After the DF measurement the samples were filtered onto GFF and their Chl $a$ content measured by the acetone extraction assay (Holm-Hansen et al. 1965). We refer to the DF-related Chl $a$ as active Chl $a$ due to the fact that the DFI represents solely the fraction of Chl $a$ that is presently involved in the photosynthesis process. Besides the DFI, we measured solar irradiation with a pyranometer (Ahlborn, Holzkirchen, Germany) and the concentration of dissolved oxygen (DO) with a galvanic DO cell (Greisinger, Regensburg, Germany). Both sensors were connected directly to a multichannel data logger (Keithley 2700, Cleveland, USA) programmed to take readings in synchronization with the DF measurements.

\section{Results}

The time change of the DFI was measured in a growing Chlorella culture during three consecutive sunny days together with incoming light and point measurements of the Chl $a$ concentration (Fig. 2). With the culture being exposed to ambient light and DF measurements without an

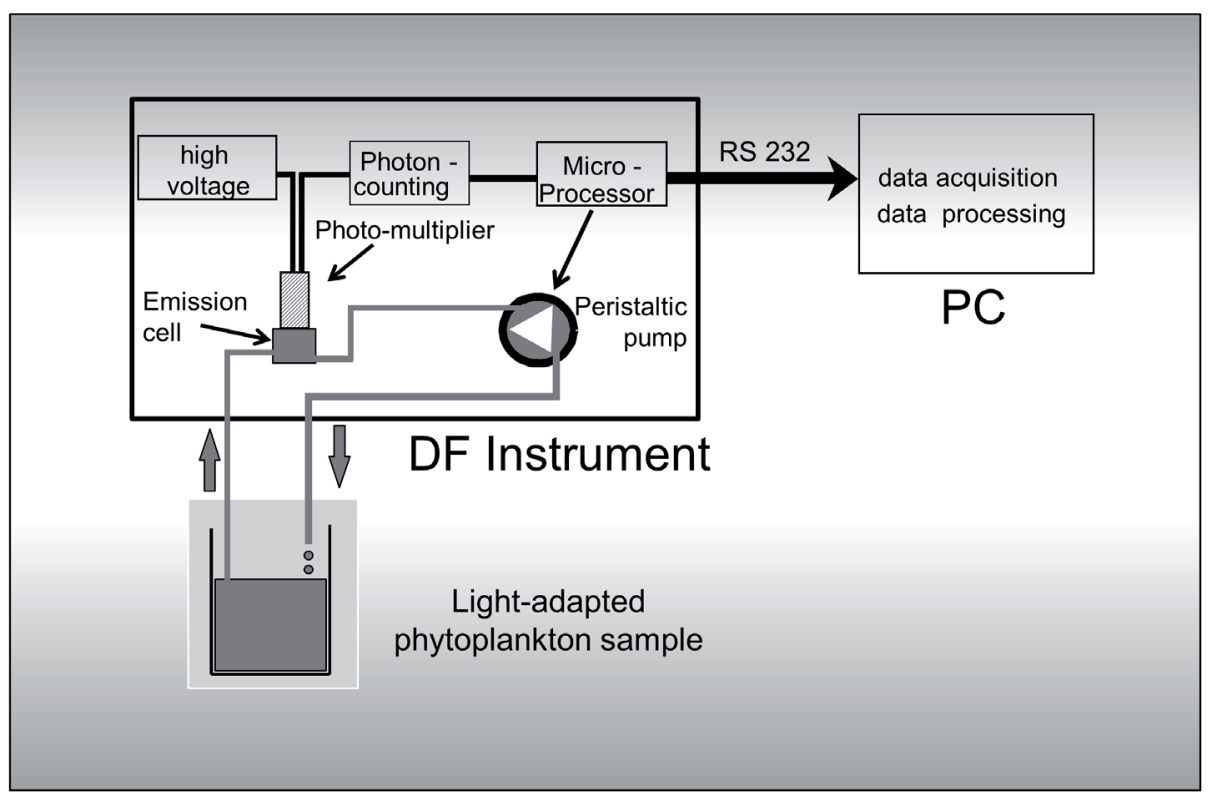

Fig. 1. Experimental setup. 


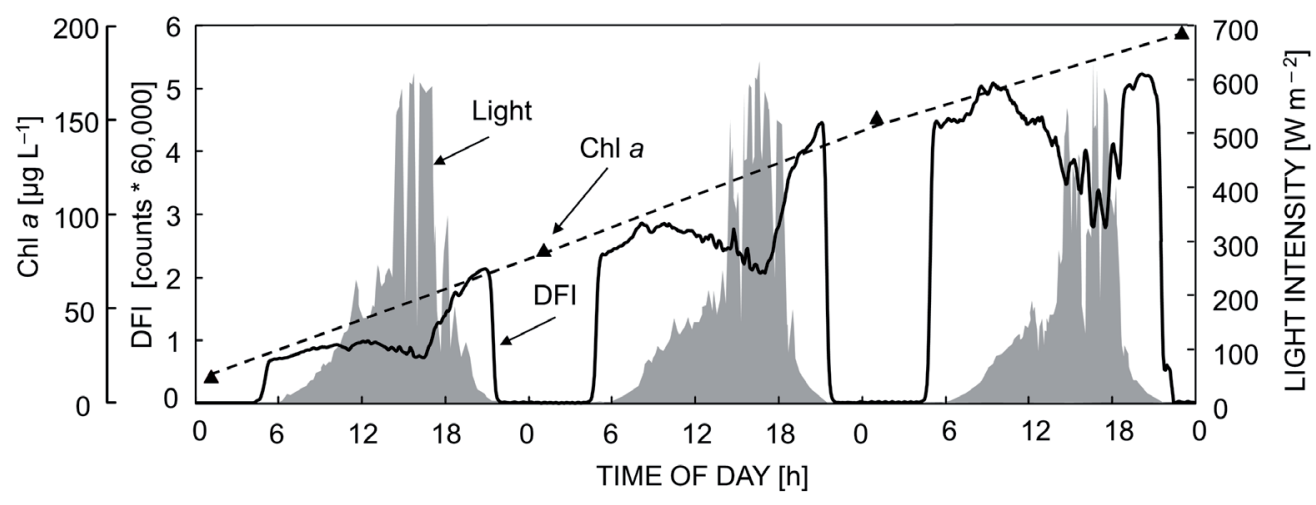

Fig. 2. Diurnal change in the DFI (black line) of a Chlorella culture exposed to ambient light. Light intensity in grey. Triangles reflect point measurements of the active $\mathrm{Chl}$ a concentrations.

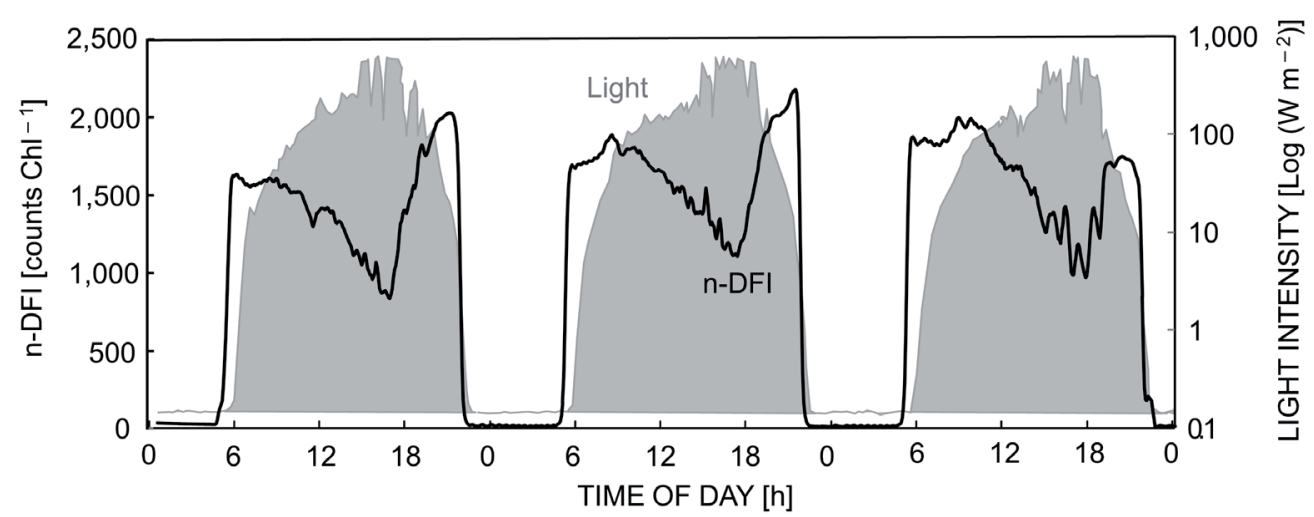

Fig. 3. Time change of the n-DFI (black line) and the log of the light intensity (grey shading) during three consecutive sunny days.

artificial light source, the signal remained zero during the night before increasing abruptly in the early morning more than an hour before the display of our light meter indicated any measureable light. During the three 24-h cycles shown, the DF curve described a distinct daily pattern that began with a steep increase in the early morning followed by a moderate increase towards the noon. When light intensities exceeded $100 \mathrm{~W} \mathrm{~m}^{-2}$, the signal began to decline to a local minimum that coincided with the peak in the daily light intensity $\left(600-700 \mathrm{~W} \mathrm{~m}^{-2}\right)$. At dusk, the integral increased again to form a prominent evening peak before dropping back to zero after sunset. During the $72 \mathrm{~h}$ of exposure, the amplitudes of the successive diurnal peaks correspond closely to the fit curve drawn through our point measurements of the Chl $a$ concentration at night time. The latter increased from 10 to $190 \mu \mathrm{g} \mathrm{L}^{-1}$. Normalization of the DFI data from Fig. 2 in combination with with the log-scale plot of the light intensities (Fig. 3) shows that the extreme increase of the DFI at the crack of dawn occurred at light intensities below the detection limit of our sensor $\left(0.14 \mathrm{~W} \mathrm{~m}^{-2}\right)$. The diurnal pattern of the n-DFI during the investigated $72-\mathrm{h}$ period led to three very similar curves with prominent morning and evening peaks and a noon depression that coincided with the light peaks.

In order to relate the n-DFI to the algal activity we added the measurement of dissolved oxygen (DO) as an indicator for photosynthetic rate (Fig. 4). While the n-DFI rose to near maximum values at 5:15, DO concentrations began to increase about one hour later when light intensities had reached $2 \mathrm{~W} \mathrm{~m}^{-2}$. During the day, net photosynthesis led to a DO pattern similar to that of overall solar radiation. A maximum of $31 \mathrm{mg}(\mathrm{DO}) \mathrm{L}^{-1}$ was measured at 15:00 h corresponding to the middle of the radiation period. Compared to the steady DO increase in the morning hours from 5 to $20 \mathrm{mg} \mathrm{L}^{-1}$, the n-DFI showed no clear trend while fluctuating around 1,500 counts $\mathrm{Chl}^{-1}$. After 13:00 $\mathrm{h}$, when light and DO increased dramatically, the n-DFI declined continuously to its minimum of 400 counts $\mathrm{Chl}^{-1}$ at 18:00 h. In the evening, the n-DFI increased again to about 1,000 counts $\mathrm{Chl}^{-1}$ while being inversely related to the intensity of the solar radiation. Noteworthy are the rapid n-DFI responses to changes in ambient light that occurred under both, high and low light conditions. The arrows in Fig 4 point out two obvious examples of this light-dependent DFI variability. After the changes obtained during exposure to high light (Figs. 2, 3, 4), we conducted an experiment aimed at the diurnal DFI and DO changes under variable light climate. During four consecutive days, a transition took place from sunny to cloudy conditions with maximum daily solar 


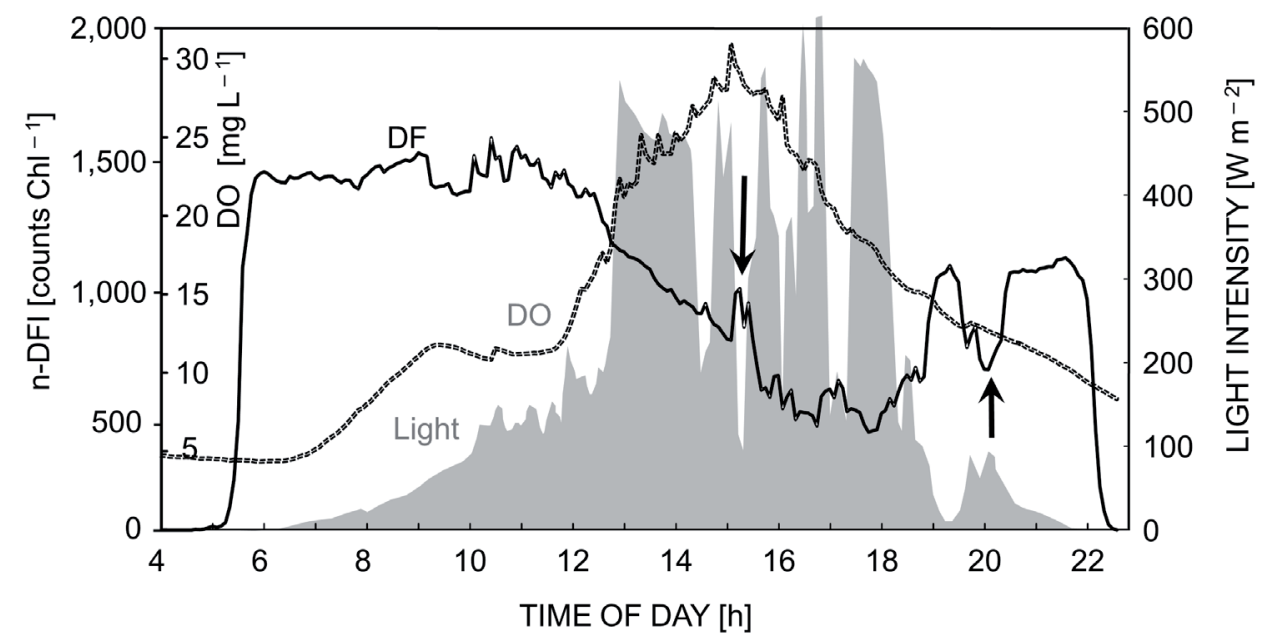

Fig. 4. Change in the n-DFI (black line), the light intensity (grey shaded area) and the dissolved oxygen concentration (dotted line) in a Chlorella vulgaris culture under ambient light. Arrows point to events explained in the text.

intensities dropping from 600 to below $100 \mathrm{~W} \mathrm{~m}^{-2}$ (Fig. 5). Similar to the results of the experiment with high light intensities (Fig. 4), the trend of the DO curve followed that of the solar radiation, which is shown best by the double peak on day 2. After a minimum before sunrise, DO concentrations increased from $4.5 \mathrm{mg} \mathrm{L}^{-1}$ to their daily maximum, i.e., $20 \mathrm{mg} \mathrm{L}^{-1}$ on day 1, 26 on day $2,25 \mathrm{mg} \mathrm{L}^{-1}$ on day 3 , and $20 \mathrm{mg} \mathrm{L}^{-1}$ on day 4. During the 96 -h period shown, Chl $a$ concentrations increased from 30 to $175 \mu \mathrm{g}$ $\mathrm{L}^{-1}$. In comparison to DO, the amplitude and shape of the DFI curve varied dramatically between days. On day 1, DFI followed the previously observed pattern (Fig. 2) with a morning peak, a depression between 11:00 and 17:00 h followed by an afternoon peak. Day 2 began with a cloudy morning and had a short sunny period in the afternoon. The resulting DFI curve became erratic with no clear trend interrupted only by a clear drop during the short high light peak in the afternoon. Day 3 was cloudy with maximum light intensities of $100 \mathrm{~W} \mathrm{~m}^{-2}$. Unlike the previously observed trends, the DF signal increased continuously towards the afternoon maximum. The last day of our sequence was overcast and rainy with light intensities remaining below $90 \mathrm{~W} \mathrm{~m}^{-2}$. This was the only instance when during day time both, DFI and DO, followed the trend of the light intensity curve.

\section{Discussion}

Our first experiment aimed at the performance of the delayed fluorescence signal of light-adapted phytoplankton under ambient light without an additional excitation light source. While in the absence of preceding data we had anticipated a gradual increase of the DFI during dawn, the abruptness and extent of the algal response in the early morning hours was intriguing (Fig. 2). The steep slope of the DFI curve was especially enhanced by its ascent from a zero-baseline, established during the preceding night phase (Figs. 2, 5). The increasing amplitude of the daily DFI maxima reflects algal growth. Unlike the relative units from prompt fluorescent methods, the DF technique provides quantitative readings and the integral represents the amount of electrons that at the beginning of photoncounting resided in the photosynthetic apparatus (Strehler and Arnold 1951). Thus, the DFI is affected by both the Chl $a$ concentration and the phytoplankton activity (Istvánovics et al. 2005, Berden-Zrimec et al. 2010). Due to the downregulation of the number of PSII involved in the lightharvesting process at light saturation, the correlation of the DFI with the Chl $a$ concentration as a biomass parameter for light-adapted algae is limited to the times when the active Chl $a$ concentration is at its daily maximum (Istvánovics et al. 2005). According to Krause et al. (1987), the measurement of the active Chl $a$ concentration using DF requires 10-20 min dark adaptation or a longer exposure to a constant light source. In our case, the growth curves based on the calibrated DFI point measurements at night corresponded well with the trend described by the maxima of the DFI curve (Figs. 2, 5). Based on this feature, it is possible to separate the light-dependent DFI changes from those caused by algal growth by normalizing the DFI by the Chl $a$ concentration, as derived from our point measurements during night time. In the case of the DFI data in Fig. 2, this results in nearly identical normalized DFI (n-DFI) curves for each of the three sunny days of the exposure experiment (Fig. 3). During day time, the n-DFI curves are very similar to those obtained previously with conventional DF instruments that followed the DF signal of a dark-adapted sample after its excitation by a constant light source (Istvánovics et al. 2005, Kurzbaum 2009, Kurzbaum et al. 2010). As in our case, the daily progress of the DF curve was characterized by morning and afternoon peaks and a noon depression displaying an opposite trend to that of the light curve. Morning peaks and noon depressions are well-known phenomena of 


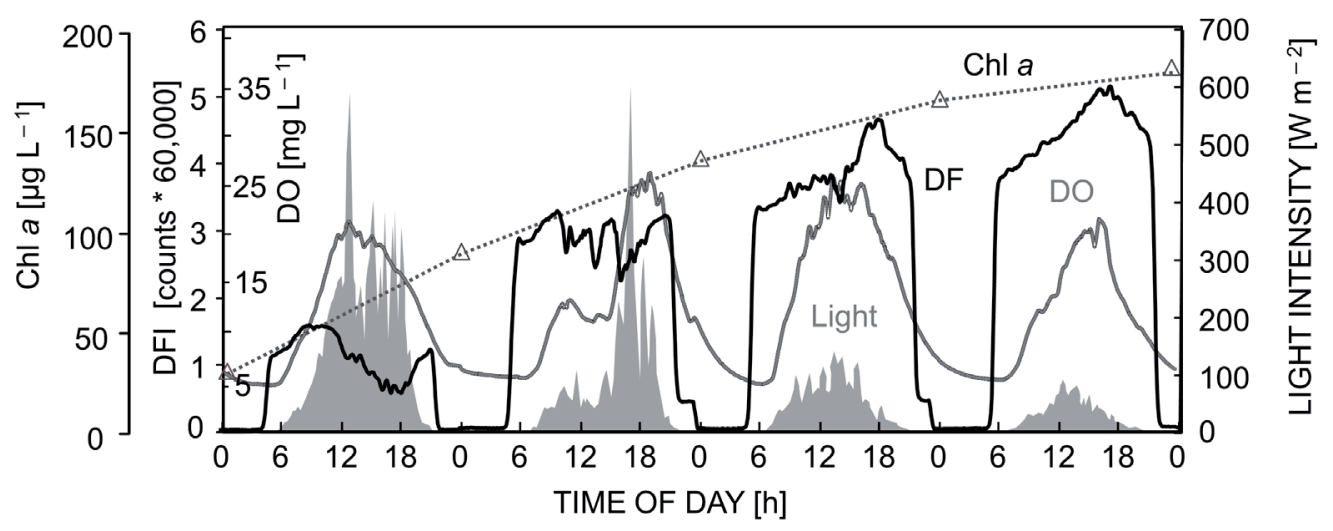

Fig. 5. Daily changes in the DFI (black line), the light intensity (grey shaded area), the dissolved oxygen concentration (dotted line) and the Chl $a$ concentration (open triangles) in a Chlorella vulgaris culture exposed to ambient light.

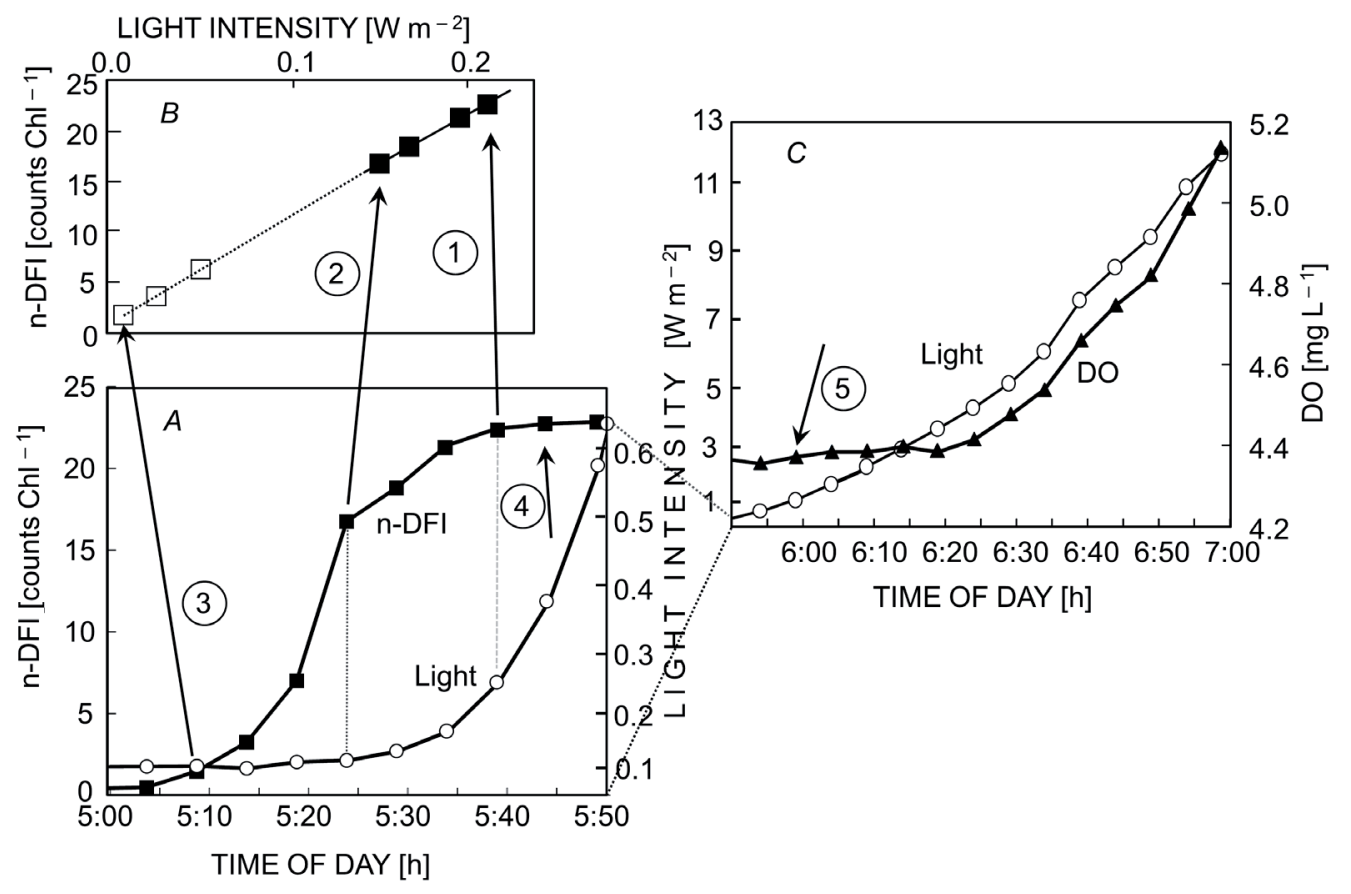

Fig. 6. n-DFI signal (filled squares), light intensity (open black circles) and DO evolution (filled triangles) at daybreak. $(A)$ The initiation of n-DFI between 5:00 and 5:50 h. (B) n-DFI at measured (filled squares) and estimated (empty squares) light intensities. (C) The initiation of DO release between 5:50 and 7:00 h. (Numbered arrows are explained in the text).

prompt phytoplankton fluorescence (Henley et al. 1991, Hanelt et al. 1993). They characterize the diurnal pattern of the DFI curve that seems to be negatively correlated to the incoming light intensity. Contrary to that, the trend of the DO evolution, as an indicator for net photosynthesis, follows closely the radiation pattern (Fig. 4). Similarly, no correlation between fluorescence and photosynthetic rate has been shown repeatedly during time series of the quantum yield of the prompt fluorescence and DO and the mid-day drop of the fluorescence signal is often described as photoinhibition (e.g., Hanelt and Nultsch 1995). In general, differences between conventional incubation and fluorescence methods were greatest for saturating light intensities (Flameling et al. 1998, Suggett et al. 2003). The physiological reasons for this disagreement, which is often observed when primary production (PP) calculated from fluorescence data is compared to oxygen production or carbon uptake measurements, has remained a major challenge regarding the fluorescence methodology (Wilhelm et al. 2004).

Nevertheless, in spite of the mid-day depression in the fluorescence signal, Suggett et al. (2006) demonstrated a tight coupling between the diel variability of cross oxygen production as derived from in situ prompt-fluorescence 
measurements with the $\mathrm{pH}$-based carbon uptake during a phytoplankton bloom. Kurzbaum et al. (2007), who measured antagonistic DF and PP trends, showed a linear correlation of the DFI with the energy utilization efficiency of the tested Chlorella culture. These findings indicate the ability of fluorescence-based photosynthetic models to be operational under high light intensities as well. The observed instantaneous response of the DF signal to changes in incoming light (Fig. 4) corroborates the interpretation of the classic mid-day depression of the fluorescence signal as being the result of a rapid photo-response, rather than that of photoinhibition (Han et al. 2000). This conclusion is substantiated further by the results from our second incubation experiment (Fig. 5), where over a period of four days the shape of the DF curve changed dramatically during gradually declining daily light intensities. When daily radiation maxima did not exceed $100 \mathrm{~W} \mathrm{~m}^{-2}$, the progress of the DF curve corresponded to the time-change of the light intensity and as such correlated well with the DO curve ( $r^{2}=0.77$; not shown). Kretsch and Gerhardt (1987) conducted a numerical analysis of the DF kinetics of algae in an analog model comparing the ETC with a sequence of capacitors and the measured DF kinetic with the amount of electrons released during their discharge. Accordingly, the DF counts represent the charge capacity of the ETC and the thylakoid membrane under the ambient conditions given at the moment of sampling. While the DFI quantifies this capacity, it does not tell the frequency of discharges needed for calculating the electron transport rate as a proxy for PP (Gilbert et al. 2000, Underwood 2002).

New in our study is the extent of the DF response to extremely low light intensities (Figs. 2-5). To emphasize this further, we have redrawn the results from Fig. 4 at a higher time resolution (Fig. 6). The first measureable increase in the n-DFI occurred at 5:10 (Fig. 6A). Fifteen min later, when light intensities reached the lower detection limit of our sensor $\left(0.14 \mathrm{~W} \mathrm{~m}^{-2}\right)$, the $n$-DFI had reached already $75 \%$ of its full scale. To our best knowledge, the lowest intensity that reportedly led to a measurable DF response was $0.183 \mathrm{~W} \mathrm{~m}^{-2}$ (Wang et al. 2004). Their study aimed at the DF signal of chloroplasts as a function of excitation intensity revealed a linear correlation between the DFI and the excitation light intensity until light saturation was reached at annualized $0.732 \mathrm{~W} \mathrm{~m}^{-2}$. Our monitoring results confirmed this linear DF response between 0.15 and $0.21 \mathrm{~W} \mathrm{~m}^{-2}$ (arrows 1 and 2, Fig 6B). Assuming the same linearity between DFI and light for lower light intensities, we can conclude from the first DF response at 5:10 that light harvesting by the algae was initiated at about $0.01 \mathrm{~W} \mathrm{~m}^{-2}$ (arrow 3, Fig. $6 B$ ).

Based on the n-DFI curve, our Chlorella culture reached light saturation (arrow 4, Fig. 6A) at $0.65 \mathrm{~W} \mathrm{~m}^{-2}$, a value similar to the previously reported $0.732 \mathrm{~W} \mathrm{~m}^{-2}$ by Wang et al. (2004). To that point, DO concentrations remained at a minimum of $4.4-4.5 \mathrm{mg} \mathrm{L}^{-1}$ and a measurable increase in DO occurred at light intensities exceeding the compensation point of $1 \mathrm{~W} \mathrm{~m}^{-2}$ (arrow 5, Fig. 6C). At light intensities exceeding $100 \mathrm{~W} \mathrm{~m}^{-2}$, the drop of the DFI indicated the beginning of the down-regulation of PSIIs involved in light harvesting (Figs. 2, 4). The fact that DO concentrations continue to follow the trend of the light intensity (Figs. 4, 5) give proof that this down-regulation is a part of an optimization process rather than an indication for photoinhibition.

Conclusions: This study presents for the first time results of DF measurements from a light-adapted phytoplankton suspension excited solely by ambient light. By following several consecutive day-night cycles, our results revealed a distinct daily pattern of the DFI as a function of the active chlorophyll concentration and an extreme rapid light response. Based on a linear relationship between the DFI and light intensities from 0.15 to a peak at $0.65 \mathrm{~W} \mathrm{~m}^{-2}$ during the transition from night to day, we can estimate that the alga responded to light intensities as low as 0.01 $\mathrm{W} \mathrm{m} \mathrm{m}^{-2}-18$ times lower than previously reported values. At $0.65 \mathrm{~W} \mathrm{~m}^{-2}$, the DFI reached a maximum confirming earlier results on DF response to light saturation. Increasing dissolved oxygen concentrations became measurable at $1.0 \mathrm{~W} \mathrm{~m}^{-2}$ when production exceeded the compensation point. During the day, the DFI varied as a function of ambient light intensities that triggered its decline above $100 \mathrm{~W} \mathrm{~m}^{-2}$. Due to this noon depression, sunny days were characterized by a DFI pattern that displayed a reverse trend compared to those of the DO evolution and the light intensity. On one hand, our findings further emphasize the on-going challenge of quantifying photosynthetic rate by fluorescence-based methods at high light intensities, while on the other hand, they do demonstrate the potential of DFI measurements for studying photosynthetic response under extremely low light conditions. Overall, our results from the multiple day-night cycles confirmed the DFI from ambient light excited algal cells as being a function of the chlorophyll concentration and of a rapid light response while standing alone it cannot provide a reliable unambiguous measure of photosynthetic activity.

\section{References}

Avron M., Schreiber U.: Properties of ATP-induces chlorophyll luminescence in chloroplasts. - Biochemistry 546: 448-454, 1979.

Berden-Zrimec M., Drinovec L., Zrimec A. et al: Delayed fluorescence in algal growth inhibition tests. - Cent. Eur. J. Biol. 2: 169-181, 2007.

Berden-Zrimec M., Drinovec L., Zrimec, A.: Delayed fluorescence. - In: Suggett D.J., Borowitzka M.A., Prášil O. (ed.): Chlorophyll $a$ Fluorescence in Aquatic Sciences: Methods and Applications. Pp. 293-309. Springer, Dordrecht 2010.

Bertsch W.F.: Two photoreactions in photosynthesis: evidence from the delayed light emission of chlorella. - P. Natl. Acad. Sci. USA 48: 2000-2004, 1962. 
Flameling I.A., Kromkamp J.: Light dependence of quantum yields for PSI1 charge separation and oxygen evolution in eucaryotic algae. - Limnol. Oceanogr. 43: 284-297, 1998.

Gerhardt V., Bodemer U.: Delayed fluorescence excitation spectrocopy: a method for determining phytoplankton composition. - Arch. Hydrobiol. Spec. Issues Adv. Limnol. 55: 101-120, 2000.

Gerhardt V., Bodemer U.: Delayed fluorescence excitation spectroscopy: A method for automatic determination of phytoplankton composition of freshwater and sediments (interstital) of algal composition of benthos. - Limnologica 28: 313-322, 1998.

Gerhardt V., Bodemer U., Eckert W.: Determination of phytoplankton colour classes: Online excitation spectroscopy of the delayed fluorescence (DF) of algae. - Verh. Internat. Verein. Limnol. 29: 306-309, 2005.

Gerhardt V., Krause H., Raba G. et al: Delayed fluorescence from photosynthetic active phytoplankton in the time-range from 1 to 55 seconds. - J. Lumin. 24-25: 799-802. 1981.

Gilbert M., Domin A., Becker A. et al: Estimation of primary productivity by chlorophyll $a$ in vivo fluorescence in freshwater phytoplankton. - Photosynthetica 38: 111-126, 2000.

Goltsev V., Zaharieva I., Chernev P. et al: Delayed fluorescence in photosynthesis. - Photosynth. Res. 101: 217-232, 2009.

Han B.-P., Virtanen M., Koponen J. et al: Effect of photoinhibition on algal photosynthesis: a dynamic model. - J. Plankton Res. 22: 865-885, 2000.

Hanelt D., Nultsch W.: Field studies of photoinhibition show noncorrelations between oxygen and fluorescence measurements in the arctic red alga Palmaria palmata. - J. Plant Physiol. 145: 31-38, 1995.

Hanelt D., Kuppertz K., Nultsch W.: Daily course of photosynthesis and photoinhibition in marine macroalgae investigated in the laboratory and feild. - Mar. Ecol. Prog. Ser. 97: 31-37, 1993.

Henley W.J., Levavasseur G., Franklin L. et al.: Diurnal responses of photosynthesis and fluorescence in Ulva rotundata acclimated to sun and shade in outdoor culture. - Mar. Ecol. Prog. Ser. 75: 19-28, 1991.

Holm-Hansen O., Lorenzen C.J., Holmes R.W. et al:: Fluorometric determination of chlorophyll. - ICES J. Mar. Sci. 30: $3-15,1965$.

Istvánovics V., Honti M., Osztoics A. et al: Continuous monitoring of phytoplankton dynamics in Lake Balaton (Hungary) using on-line delayed fluorescence excitation spectroscopy. - Freshwater Biol. 50: 1950-1970, 2005.

Jursinic P.: Delayed fluorescence: current concepts and status. In: Govindjee, Amesz J., Fork D.C. (ed.): Light Emission by Plants and Bacteria. Pp. 292-328. Academic Press, San Diego 1986.

Katsumata M., Koike T., Nishikawa M. et al.: Rapid ecotoxicological bioassay using delayed fluorescence in the green alga Pseudokirchneriella subcapitata. - Water Res. 40: 33933400, 2006.

Krause H., Dirnhofer P., Gerhardt V.: The application of delayed fluorescence of phytoplankton in ecology. - Arch. Hydrobiol. Beih. Ergebn. Limnol. 29: 55-62, 1987.
Kretsch G., Gerhardt V.: Numerical analysis of delayed fluorescence of algae. - Arch. Hydrobiol. Beih. Ergebn. Limnol. 29: 47-54, 1987.

Kurzbaum E.: Delayed fluorescence as a simple and rapid measurment tool for active chlorophyll concentration, phytoplankton compositions and a possible tool for monitoring photosynthetic traits of phytoplankton. - In: Kersey W., Munger S.P. (ed.): Marine Phytoplankton. Pp. 351-354. Nova Science, New York 2009.

Kurzbaum E., Beer S., Eckert W.: Alterations in delayed and direct phytoplankton fluorescence in response to the diurnal light cycle. - Hydrobiologia 639: 197-203, 2010.

Kurzbaum E., Eckert W., Yacobi Y.Z.: Delayed fluorescence as a direct indicator of diurnal variation in quantum and radiant energy utilization efficiencies of phytoplankton. Photosynthetica 45: 562-567, 2007.

Leunert F., Grossart H.-P., Gerhardt V. et al.: Toxicant induced changes on delayed fluorescence decay kinetics of cyanobacteria and green algae: A rapid and sensitive biotest. - PLoS ONE 8: e63127, 2013.

Melcarek P.K., Brown G.N.: Effects of chill stress on prompt and delayed chlorophyll fluorescence from leaves. - Plant Physiol. 60: 822-825, 1977

Mellvig S., Tillberg J.-E.: Transient peaks in the delayed luminescence from Scenedesmus obtusiusculus induced by phosphorus starvation and carbon dioxide deficiency. Physiol. Plantarum 68: 180-188, 1986.

Monti M., Zrimec A., Beran A. et al.: Delayed luminescence of Prorocentrum minimum under controlled conditions. Harmful Algae 4: 643-650, 2005.

Moss B.: The influence of environmental factors on the distribution of freshwater algae: an experimental study: I. Introduction and the influence of calcium concentration. - J. Ecol. 60: 917-932, 1972.

Strehler B., Arnold W.: Light production by green plants. - J. Gen. Physiol. 34: 809-820, 1951.

Suggett D.J., Maberly S.C., Geider R.J.: Gross photosynthesis and lake community metabolism during the spring phytoplankton bloom. - Limnol. Oceanogr. 51: 2064-2076, 2006.

Suggett D.J., Oxborough K., Baker N.R. et al.: Fast repetition rate and pulse amplitude modulation chlorophyll $a$ fluorescence measurements for assessment of photosynthetic electron transport in marine phytoplankton. - Eur. J. Phycol. 38: 371 384, 2003.

Underwood G.: Adaptations of tropical marine microphytobenthic assemblages along a gradient of light and nutrient availability in Suva Lagoon, Fiji. - Eur. J. Phycol. 37: 449-462, 2002.

Wang C., Xing D., Chen Q.: A novel method for measuring photosynthesis using delayed fluorescence of chloroplast. Biosens. Bioelectron. 20: 454-459, 2004.

Wilhelm C., Becker A., Toepel J. et al:: Photophysiology and primary production of phytoplankton in freshwater. - Physiol. Plantarum. 120: 347-357, 2004.

Yacobi Y.Z., Gerhardt V., Gonen-Zurgil Y. et al.: Delayed fluorescence excitation spectroscopy: A rapid method for qualitative and quantitative assessment of natural population of phytoplankton. - Water Res. 32: 2577-2582, 1998.

(C) The authors. This is an open access article distributed under the terms of the Creative Commons BY-NC-ND Licence. 